\title{
Resultados en \\ 125 casos de Eclampsia
}

Dres. Carlos Martinez Sáenz, Jesús Alberto Gómez Palacino, Fernando Sánchez Torres y Carlos R. Silva Mojica

Del servicio de Toxemias del Instituto Materno Infantil de Bogotá

Presentamos los resultados obtenidos con el tratamiento seguido en el Servicio de Toxemias del Instituto Materno Infantil de Bogotá, en 125 casos de Eclampsia observados en el lapso comprendido entre Marzo de 1959 y Agosto de 1960. Durante estos 18 meses fueron atendidas 600 pacientes con distintos grados de Toxemia gravídica.

Por la aparición cronológica de la Eclampsia, las pacientes fueron clasificadas así: 65 con Eclampsia ante-parto, 41 con Eclampsia intra-parto y 19 con Eclampsia post-parto. En los casos en que las convulsiones se prolongaron en más de una de las etapas del estado puerperal, se agruparon en aquélla en que se iniciaron.

\section{CUADRO No I \\ ECLAMPSIA ANTE-PARTO}

TOTAL DE CASOS:

Con feto vivo al ingreso:

Con feto muerto al ingreso:

No repitieron convulsiones después del tratamiento:

Repitieron convulsiones después del tratamiento:

PARTOS:

Espontáneos:

Inducidos:

35

Forceps:

Extracción podálica:

Cesáreas:

ESULTADOS:

Mortalidad materna:

Mortalidad fetal: a) Ante-Parto:

b) Intra-Parto: 


\section{COMENTARIOS}

$1^{\circ}$ - Se registraron 62 partos en 65 casos, pues 3 fetos permanecían in útero en el momento de la muerte de la paciente.

$2^{9}$ - Se practicaron 5 cesáreas por indicación obstétrica:

2 por sufrimiento fetal (circulares del cordón).

2 por desproporción céfalo-pélvica.

1 por abruptio placentae.

$3^{\circ}$ - Las 4 pacientes que fallecieron presentaron accidente cerebrovascular. Más adelante se estudian en detalle estos casos.

$4^{o}$ - En relación a la mortalidad fetal, los 11 casos registrados corresponden a fetos fallecidos en el Servicio.

\section{CUADRO No II \\ ECLAMPSIA INTRA-PARTO}

TOTAL DE CASOS:

Con feto vivo al ingreso:

Con feto muerto al ingreso:

No repitieron convulsiones después del tratamiento:

Repitieron convulsiones después del tratamiento:

PARTOS:

Espontáneos:

Forceps:

Extracción podálica:

Cesáreas:

RESULTADOS:

Mortalidad materna:

Mortalidad fetal: 


\section{COMENTARIOS}

$1^{\circ}$ - Se registran 42 partos en 41 casos, pues hubo un parto gemelar.

$2^{0}$ - Se practicaron 7 cesáreas por indicación obstétrica:

4 por sufrimiento fetal, 2, en pacientes con pelvis estrecha.

1 por desproporción pelvi-fetal.

1 por pelviviciación.

1 por inercia secundaria.

$3^{0}$ - El caso de mortalidad materna anotado, corresponde a una paciente que falleció 6 días después del parto por insuficiencia renal aguda.

$4^{\text {o }}$ - El caso de mortalidad fetal registrado corresponde a un segundo gemelo que falleció intra-parto por anoxemia debida a hipotensión arterial por la rqquianestesia.

\section{CUADRO No III}

\section{ECLAMPSIA POST-PARTO}

TOTAL DE CASOS:

No repitieron convulsiones después del tratamiento:

Repitieron convulsiones después del tratamiento:

RESULTADOS:

Mortalidad materna:

0

\section{UUMENTARIOS}

Todas las pacientes tuvieron su parto fuera del Servicio. 


\section{MORTALIDAD MATERNA}

Cuadro No. IV

\begin{tabular}{|c|c|c|c|c|c|c|}
\hline HISTORIA & EDAD & ECLAMPSIA & $\begin{array}{l}\text { FETO AL } \\
\text { INGRESO }\end{array}$ & $\begin{array}{l}\text { ESTANCIA EN } \\
\text { SERVICIO }\end{array}$ & PARTO & CAUSA DE LA MUERTE \\
\hline 68457 & 23 & Ante-Parto & Vivo & 50 minutos & No & $\begin{array}{l}\text { Accidente } \\
\text { cerebro-vascular } \\
\text { Edema agudo del } \\
\text { puimóo }\end{array}$ \\
\hline 72894 & 17 & Ante-Parto & Muerto & 8 horas & No & $\begin{array}{l}\text { Accidente } \\
\text { cerebro-vascular }\end{array}$ \\
\hline 50775 & 29 & Ante-Parto & Muerto & 12 horas & No & $\begin{array}{l}\text { Accidente } \\
\text { cerebro-vascular }\end{array}$ \\
\hline 68729 & 40 & Ante-Parto & Muerto & 7 días & Sí & $\begin{array}{l}\text { Insuficiencia } \\
\text { Renal aguda }\end{array}$ \\
\hline 61270 & 22 & Intra-Parto & Muerto & 60 minutos & Sí & $\begin{array}{l}\text { Accidente } \\
\text { cerebro-vascular } \\
\text { Edema agudo } \\
\text { del pulmón }\end{array}$ \\
\hline
\end{tabular}

\section{COMENTARIOS}

$1^{\circ}$ - De las 4 pacientes fallecidas por accidente cerebro-vascular, 2 presentaban esta complicación en el momento de su ingreso, y en 2 fue advertida antes de 8 horas de permanencia en el Servicio.

$2^{\circ}-$ De las 5 pacientes, sólo una repitió convulsiones (un ataque) durante su estancia en el Servicio.

$3^{\circ}$ - La paciente fallecida por insuficiencia renal aguda, ingresó después de haber presentado 15 ataques convulsivos, iniciados 27 horas antes. Después del tratamiento no presentó ninguna convulsión. Tuvo un parto espontáneo 6 horas después. Falleció al $7^{\circ}$ día de puerperio. 
$4^{\text {O }}$ - Cuatro pacientes ingresaron con feto muerto in-útero. En el caso restante, habiendo ingresado con feto vivo, la agravación rápida y progresiva impidió la resolución obstétrica adecuada.

\section{RESUMEN Y CONCLUSIONES}

$1^{\text {? }}$ - Se presentan 125 casos de Eclampsia sobre un total de 600 pacientes con distintos grados de Toxemia gravídica, atendidas en el Siervicio correspondiente del Instituto Materno Infantil de Fiogotá, durante 18 meses. De acuerdo con estas cifras el porcentaje de Eclampsia representa el $20.8 \%$.

$2^{\circ}$ - Los datos anteriores dan idea de la magnitud del problema médico-social que representa la toxemia gravídica en nuestro medio.

$3^{\circ}$ - Sobre 125 casos de Eclampsia, solamente 33 pacientes repitieron los ataques convulsivos después de la aplicación del tratamiento, lo cual corresponde a un $26.4 \%$.

$4^{0}$ - No practicamos ninguna intervención cesárea por Eclampsia.

$5^{0}$ - La mortalidad materna por Eclampsia en las pacientes atendidas por nosotros, fué de $4 \%$. La mortalidad fetal de $12.9 \%$, sobre los fetos que ingresaron vivos al Servicio.

$6^{\circ}$ - Las cifras de mortalidad materno-fetal presentadas, demuestran la bondad del tratamiento de la Eclampsia por nosotros preconizado.

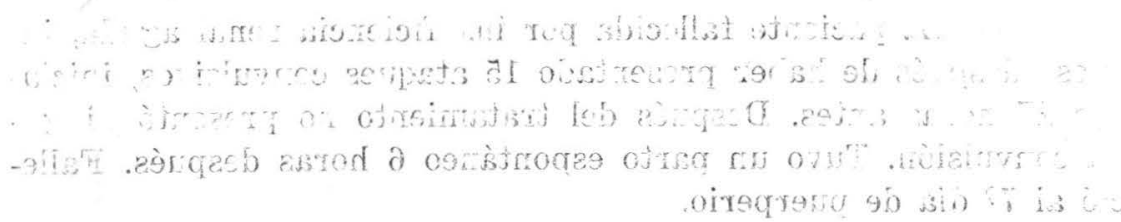

